\title{
OSTEOPOROSIS AND FRACTURE OF THE FEMORAL NECK IN THE SOUTH AFRICAN BANTU
}

\author{
L. Solomon, Johannesburg, South Africa \\ From the Department of Orthopaedic Surgery, University of the Witwatersrand
}

The close association of fracture of the femoral neck and osteoporosis in the aged has led to the notion that this is, in a sense, a pathological fracture. This is not a new concept. Over 100 years ago Astley Cooper (1824) noted the relationship between old age and fragility of the bones, which ". . . become thin in their shell and spongy in their texture." More recently epidemiological studies have shown a rising incidence of fracture of the femoral neck in old age, and particularly in women after the menopause, which closely follows the age and sex distribution of osteoporosis in the populations studied (Stewart 1955, Buhr and Cooke 1959, Bauer 1960).

In terms of hospital statistics and patient morbidity this is becoming an increasingly serious problem. Thus, a study carried out in the Eastern Region of Scotland suggests that the total number of patients with femoral neck fractures may be expected to increase by 50 per cent between 1952 and 1975 (Stewart 1955, 1958). It is estimated that there have been approximately 1,000 fractures of the femoral neck among the white population of three and a half million in South Africa during the past year and, given the present trend in population, this figure may be doubled by the turn of the century.

Against this background there stands the casual observation that fractures of the femoral neck are apparently uncommon in the Bantu of South Africa, and the work of Jackson (1961), Seftel, Abrams, Charlton, Abrahams, Rubenstein, Jacobs and Bothwell (1963) and Walker (1965) suggests that the pattern and distribution of osteoporosis show a similar difference in the Bantu and white populations of this country. Outside South Africa, too, racial differences of this kind have been sought. Vincent and Urist (1961) and Smith, Eyler and Mellinger (1960) noted the absence of negroes among osteoporotic patients drawn from heterogeneous United States communities, and Gyepes, Mellins and Katz (1962) commented on the comparatively small number of femoral neck fractures in American negroes.

However, these observations have been based on simple ratio studies of patients in hospitals or institutions. They are corroborated to some extent by the results of a demographic survey of femoral neck fractures in American negroes and whites (Bollet, Engh and Parson 1965). Unfortunately, though, in the latter study the population at risk was too small to permit definitive epidemiological analysis.

The present investigation is part of a large scale epidemiological study of osteoporosis in South African populations of different racial, cultural, economic and dietary background. Further studies on vertebral and femoral osteoporosis in other population groups, both urban and rural, will be reported in due course.

\section{FEMORAL NECK FRACTURE AS AN INDEX OF SENILE OSTEOPOROSIS}

The epidemiological method depends on the demonstration of a reasonably clear cut phenomenon which can be measured and compared in different populations. The choice of a major complication, such as a fracture, as an index of osteoporosis is justified by the absence of any well defined and agreed criteria of osteoporosis applicable to a large epidemiological study. The validity of femoral neck fracture as the index chosen is based on the following premises: 1) In old age, at a time of lessening activity and exposure to serious stresses, certain 
fractures nevertheless occur with increasing frequency. These are compression fractures of the vertebrae and fractures of the distal end of the radius and the femoral neck, all of which are uncommon in young adults. 2) It is generally agreed that the prevalence of osteoporosis in Western European and American communities rises steadily with age and ranges from about 5 per cent in the fifth decade to over 30 per cent in the eighth decade, with women predominating over men in a ratio of $2: 1$ or $3: 1$ (Gershon-Cohen, Rechtman, Schraer and Blumberg 1953; Smith et al. 1960; Urist 1960; Vincent and Urist 1961; Nordin 1963). Previous epidemiological studies have shown an identical trend in the incidence of femoral neck fractures in Western European people (Stewart 1955, Bauer 1960). 3) The degree of trauma causing femoral neck fracture in the aged is usually minimal, suggesting an increased fragility of this area of the skeleton. 4) Histological and radiographic examinations have shown a higher incidence of osteoporosis in patients with femoral neck fracture than in a control group (Stevens, Freeman, Nordin and Barnett 1962). 5) Vose, Stover and Mack (1961), in a quantitative study of femoral bone strength in senile osteoporosis, demonstrated that although there was no diminution in strength per unit volume of cortical bone, the total strength of the osteoporotic femur under static loading was 40 per cent less than that of normal bone.

\section{DEMOGRAPHY}

In epidemiological studies carried out in modern Western European countries such important factors as the presence of a reasonably settled and generally enlightened community, accurate census figures and reliable hospital statistics are very much taken for granted. By contrast, the value of such studies in underdeveloped communities may lie precisely in the

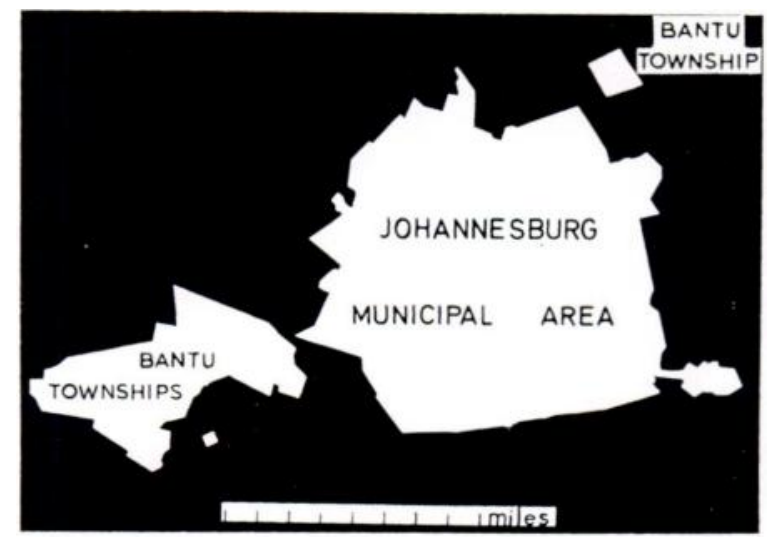

Fig. 1

Map showing the extent of the Johannesburg metropolitan area.

exclusion of these sophisticated standards and the maintenance of those primitive cultural and environmental influences that could determine differences in disease incidence. The collection and interpretation of information in these circumstances is often extremely difficult, complicated as they are by factors such as traditional fears and taboos, failure to seek medical attention, language difficulties, the problems of estimating age, and the accurate assessment of the population at risk. To permit an adequate evaluation of the material presented here the demographic features will be discussed in detail.

The population studied-The negroes of South Africa belong to a single large group known as the Southern Bantu. At the 1960 census they numbered eleven million. They have been subdivided geographically into three separate groups cutting haphazardly across the normal tribal divisions. There are those who have continued to reside in the tribal homelands; they comprise about 43 per cent of the total. Another 30 per cent live and work on farms outside

VOL. 50 B, NO. 1, FEBRUARY 1968 
the tribal areas. The remaining 27 per cent now live more or less permanently in the urban areas where they work for the most part as unskilled and semi-skilled labourers. Migratory labourers who pass back and forth between the rural and the urban areas have for some years been restricted to a minimum, excepting those who work under contract for the gold mining industry. This latter group has been excluded from the present study.

The present investigation has been confined to the Bantu population of the Johannesburg Metropolitan Area. A small portion of this population lives and works in the Johannesburg Municipal Area, but by far the greater part is settled permanently in the peri-urban townships

TABLE I

Bantu Population of Johannesburg in 1960, Compared with the Standard Population of the UnIted States of AMerica for 1950

\begin{tabular}{|c|c|c|c|c|}
\hline \multirow{3}{*}{$\begin{array}{c}\text { Age } \\
\text { (years) }\end{array}$} & \multirow{3}{*}{$\begin{array}{c}\text { Standard } \\
\text { population } \\
\text { U.S.A. } \\
\text { 1950* }\end{array}$} & \multicolumn{3}{|c|}{ Johannesburg Bantu, 1960} \\
\hline & & \multicolumn{2}{|c|}{ Males } & \multirow{2}{*}{ Females } \\
\hline & & Total & $\begin{array}{c}\text { Excluding } \\
\text { mineworkers }\end{array}$ & \\
\hline $0-4$ & 107,258 & 39,728 & 39,728 & 41,044 \\
\hline $5-9$ & 87,591 & 31,217 & 31,217 & 33,597 \\
\hline $10-14$ & 73,785 & 22,749 & 22,749 & 25,527 \\
\hline $15-19$ & 70,450 & 22,126 & 22,126 & 22,965 \\
\hline $20-24$ & 76,191 & 31,736 & 24,765 & 29,992 \\
\hline $25-29$ & 81,237 & 37,675 & 30,962 & 32,876 \\
\hline $30-34$ & 76,425 & 33,888 & 30,015 & 28,050 \\
\hline $35-39$ & 74,629 & 33,489 & 30,391 & 22,845 \\
\hline $40-44$ & 67,712 & 28,506 & 26,957 & 17,879 \\
\hline $45-49$ & 60,190 & 21,748 & 20,715 & 13,274 \\
\hline $50-54$ & 54,893 & 12,558 & 12,252 & 8,189 \\
\hline $55-59$ & 48,011 & 8,990 & 8,761 & 4,895 \\
\hline $60-64$ & 40,210 & 4,485 & 4,385 & 3,544 \\
\hline $65-69$ & 33,199 & 2,312 & 2,262 & 2,423 \\
\hline $70-74$ & 22,641 & 1,302 & 1,257 & 1,835 \\
\hline $75-79$ & 14,725 & 845 & 820 & 1,191 \\
\hline 80 & 10,853 & 624 & 604 & 878 \\
\hline Unspecified & - & 937 & 937 & 361 \\
\hline Total & $1,000,000$ & 334,911 & 310,903 & 291,455 \\
\hline
\end{tabular}

* Morbidity from Cancer in the U.S. Public Health Monograph No. 56 ,

Appendix I, Table 3. U.S. Govt. Printing Office, Washington. 1959.

(Fig. 1). This is an ideal community for epidemiological study. 1) It is balanced numerically by a white population of Western European descent which constitutes a comparative standard in such investigations. 2) The urban Bantu have remained culturally and racially distinct from their white countrymen, and yet have not retained their " tribal" ways to such a degree that they would fail to seek medical advice for any serious illness. 3) The community has become 
reasonably stable, partly as a result of legislation which restricts migration to the urban area and partly as a result of extensive housing schemes in the townships. Already in 1951 a sample study indicated that 34 per cent of people living in the townships were born in Johannesburg and another 31 per cent had lived in Johannesburg for more than ten years (Batson and Feldman 1951). 4) The entire community is served by general hospitals which are part of the Teaching Hospital Group associated with the Witwatersrand Medical School. There are no private nursing facilities for Bantu patients outside these hospitals; thus every patient requiring admission can be traced in the hospital records. 5) The rising level of education and daily contact with the industrial society of Johannesburg have removed many of the barriers to free communication between the investigator and the population under study. With the assistance of Bantu social workers and interpreters the language difficulties, too, have been overcome.

The population at risk-The estimate of the population at risk was based on the 1960 census and is compared with the Standard United States population structure (Table I). The figures for the five-year age groups above seventy were calculated as proportions of the total for the "seventy years and over" by referring to the corresponding figures in the Standard United States population. In the final calculations the mine workers were excluded; they are a migratory population living quite separately on the mine properties and treated in special hospitals administered by the Chamber of Mines.

A sociological survey of one of the Johannesburg townships showed that the previous census probably underestimated the true population by 10 per cent, all age groups being affected equally (Higginson and Oettlé 1960). No adjustment has been made for this discrepancy since use of the census figure would tend, if anything, to exaggerate slightly the fracture rates.

The problems of estimating age in the Bantu have been discussed at length by Oettlé $(1955,1958)$ and Higginson and Oettlé (1960).

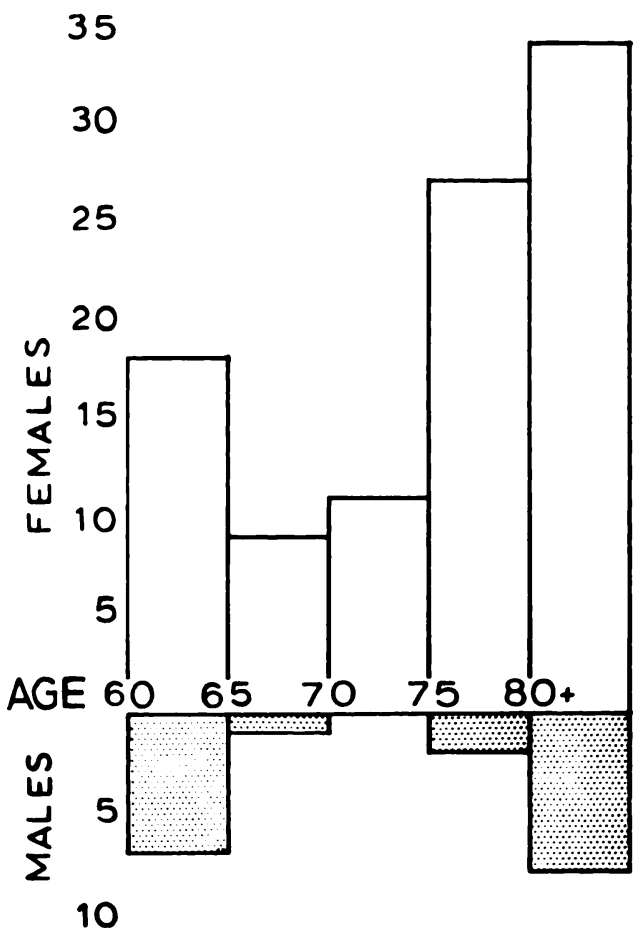

FIG. 2

Sex and age distribution of chronic invalids examined for femoral neck fracture. (Pimville survey: 117 persons.) By careful cross checking and reference to well known events in the history of the particular group, an acceptable degree of accuracy has been achieved. Moreover, the results of this particular investigation indicate that age by itself is not the overriding factor that it appears to be in comparable studies in Europeans.

Non-attendance and missed cases-One of the most serious sources of error in calculating disease incidence in backward communities arises from cases not coming under medical attention. This may apply even to a serious incident such as a femoral neck fracture.

In a survey of invalidism in one of the Johannesburg Bantu townships Hearn (1964) found that, out of 162 completely incapacitated invalids, forty had not consulted a doctor at all. A radiographic survey of the same community was, therefore, carried out to discover whether any significant number of the aged and bedridden had femoral neck fractures (or any other serious conditions around the hip) which had gone undetected and untreated. A sample of 117 chronic invalids was collected for radiographic examination of the pelvis with a portable unit (Fig. 2 and Table II). Four cases of femoral neck fracture were found-three in males 
and one in a female. They were all attributed to serious injuries, were known to the subjects in question and had already been recorded in the total fracture survey.

It was concluded that no significant number of cases were missed because of non-attendance at one of the hospitals, and that the total population could be regarded as the population at risk. The sample studied-Every case of fracture of the proximal end of the femur admitted to the Teaching Hospital Group between 1950 and 1964 was included in the original survey. The seven annual periods centred on the last census year (1960) were selected for definitive study.

TABLE II

RADIOGRAPHiC SURVEY OF 117 Aged INVALIDS IN THE JOHANNESBURG BANTU TOWNSHIPS

\begin{tabular}{|c|c|c|c|}
\hline \multirow{2}{*}{ Radiological diagnosis } & \multicolumn{3}{|c|}{ Number of cases } \\
\hline & Male & Female & Total \\
\hline Fracture of the femoral neck & 3 & 1 & 4 \\
\hline Osteoarthritis of the hip & 4 & 11 & 15 \\
\hline Arthrokatadysis. & 0 & 9 & 9 \\
\hline
\end{tabular}

"Femoral neck fracture" was defined as any fracture across the width of the femur proximal to and including the lesser trochanter. The diagnosis was determined in each case from the combined clinical, radiographic and operative records. These cases were then analysed as to sex, age, type of trauma and precise level of fracture.

In the fracture surveys reported by Stewart (1955) and Bauer (1960) only those fractures produced by minor trauma were included, these being reasonably attributed to the underlying osteoporosis. In the present survey, however, all femoral neck fractures were included, partly because of the difficulty of determining precisely what constitutes minor trauma in any particular society, but chiefly because, in a labouring community exposed to a high incidence of serious trauma, an unduly large section of the population would be excluded by limiting the survey to those cases resulting from minor trauma.

Because of the extraordinarily small numbers involved, no distinction has been made in the final analysis between cervical fractures and intertrochanteric fractures. The following categories, however, were excluded completely: 1) patients under thirty years of age; and 2) pathological fractures caused by definite underlying disease.

\section{THE METHOD OF CALCULATING FRACTURE RATES}

Simple ratio studies are of little value in comparing the susceptibility to femoral neck fracture of one population group with another of different age and sex structure. Only by relating the number of fractures to the population at risk in each age and sex group may one achieve an adequate basis for comparison. Stewart (1955) and Bauer (1960) calculated the age-specific rates for each of the populations studied and these have been compared with the results of the present survey (Table IV and Fig. 3).

However, the population at risk among the urban Bantu diminishes much more rapidly with age than in the case of white groups. If the fracture incidence is expressed as a rate per 100,000 per annum for quinquennial age groups the number of cases involved will be so small as to produce considerable fluctuations as a result of random variations. The method of direct standardisation to the United States population for 1950 was, therefore, employed; the age-specific fracture rates were applied to this population to indicate the number of fractures that might be expected at these rates. 


\section{RESULTS}

The numbers of femoral neck fractures by age and sex for each year from 1957 to 1963 are given in Table III, with the age-specific rates and the standardised rates in Tables IV and $\mathrm{V}$. There is undoubtedly a rise in the fracture incidence over the age of sixty years, and the detailed analysis indicates that this is accounted for entirely by an increase in fractures produced by minimal trauma. Nevertheless, these rates are a mere fraction of those reported in the European surveys (Fig. 3).

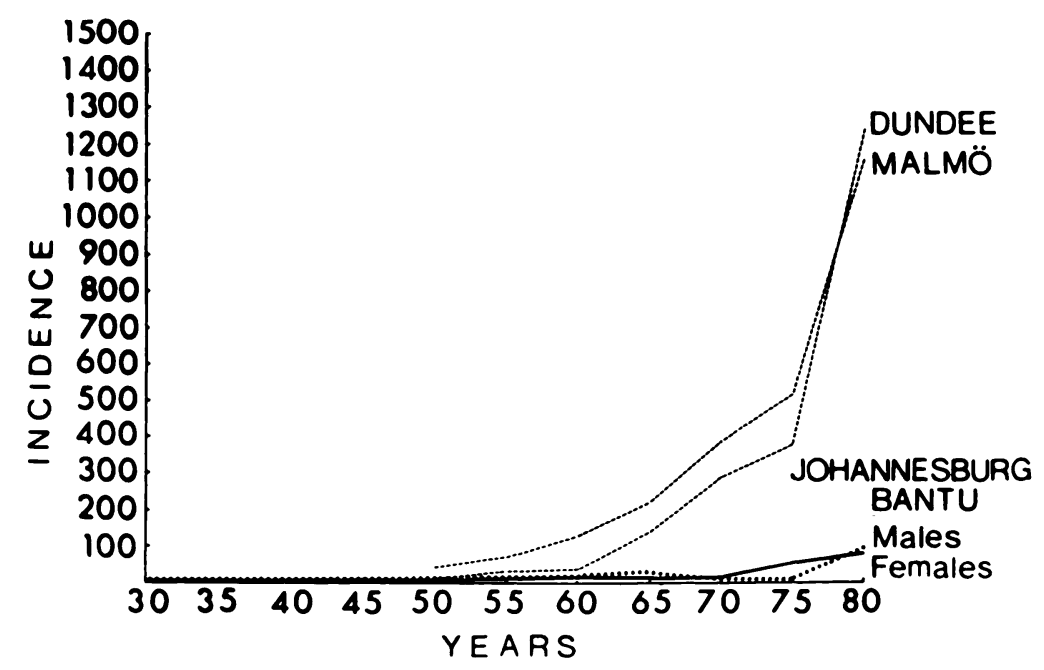

FIG. 3

Age-specific incidence of fractures of the femoral neck in Western European populations (Dundee and Malmö) and in Johannesburg Bantu.

TABLE III

Femoral Neck Fractures in Johannesburg Bantu Males and Females (1957-63)

\begin{tabular}{|c|c|c|c|c|c|c|c|c|c|c|c|c|c|c|c|c|}
\hline \multirow{3}{*}{$\begin{array}{c}\text { Age } \\
\text { (years) }\end{array}$} & \multicolumn{14}{|c|}{ Number of fractures in each year } & \multirow{2}{*}{\multicolumn{2}{|c|}{$\begin{array}{l}\text { Average } \\
\text { per year }\end{array}$}} \\
\hline & \multicolumn{2}{|c|}{1957} & \multicolumn{2}{|c|}{1958} & \multicolumn{2}{|c|}{1959} & \multicolumn{2}{|c|}{1960} & \multicolumn{2}{|c|}{1961} & \multicolumn{2}{|c|}{1962} & \multicolumn{2}{|c|}{1963} & & \\
\hline & Male & Female & Male & Female & Male & Female & Male & Female & Male & Female & Male & Female & Male & Female & Male & Female \\
\hline $30-34$ & 1 & & 3 & & 1 & & & & & & 1 & & 1 & & 1 & \\
\hline $35-39$ & 1 & 1 & 2 & & & & & 1 & & & 1 & & 1 & & 0.7 & 0.3 \\
\hline $40-44$ & & & 1 & & & & 1 & 3 & 1 & & 2 & & 1 & 1 & 0.85 & 0.6 \\
\hline $45-49$ & 1 & & & & & & & & 1 & & 3 & & & 1 & 0.7 & $0 \cdot 1$ \\
\hline $50-54$ & & & 1 & & 2 & 1 & & & 1 & & & 1 & 2 & & 0.7 & 0.3 \\
\hline $55-59$ & 2 & & 1 & & 1 & 2 & 1 & 1 & 1 & & & & & 1 & 0.85 & 0.6 \\
\hline $60-64$ & & 1 & 1 & 2 & 1 & & & & ! & & 1 & & 1 & 1 & 0.6 & 0.6 \\
\hline $65-69$ & 1 & & & & 1 & & & & & 1 & 1 & 1 & 1 & & 0.6 & 0.3 \\
\hline $70-74$ & & 1 & & 1 & & & & & & & & & 1 & & 0.1 & 0.3 \\
\hline $75-79$ & & & & & & 1 & & & & 2 & & & & 1 & & 0.6 \\
\hline 80 & 3 & 2 & & 1 & & 1 & 1 & & & & & & 1 & 1 & 0.7 & 0.7 \\
\hline Total & 9 & 5 & 9 & 4 & 6 & 5 & 3 & 5 & 3 & 3 & 9 & 2 & 9 & 6 & 6.9 & $4 \cdot 3$ \\
\hline
\end{tabular}

VOL. $50 \mathrm{~B}$, NO. 1, FEBRUARY 1968 
TABLE IV

Age-Specific Incidence of Fractures of the Femoral Neck in Dundee, IN MALMö aNd in JohanNesburg BaNTU

\begin{tabular}{|c|c|c|c|c|}
\hline \multirow{2}{*}{$\begin{array}{c}\text { Age } \\
\text { (years) }\end{array}$} & \multicolumn{3}{|c|}{ Number of fractures per 100,000 per annum } \\
\cline { 2 - 5 } & $\begin{array}{c}\text { Dundee, Scotland } \\
\text { (Stewart 1958) }\end{array}$ & $\begin{array}{c}\text { Malmö, Sweden } \\
\text { (Bauer 1960) }\end{array}$ & $\begin{array}{c}\text { Bantu males } \\
(1957-63)\end{array}$ & $\begin{array}{c}\text { Bantu females } \\
(1957-63)\end{array}$ \\
\hline $30-34$ & Females only & Females only & & \\
$35-39$ & & & 3 & 0 \\
$40-44$ & & & 2 & 1 \\
$45-49$ & & & 3 & 3 \\
$50-54$ & 6 & 40 & 3 & 1 \\
$55-59$ & 33 & 70 & 6 & 4 \\
$60-64$ & 37 & 120 & 10 & 12 \\
$65-69$ & 138 & 220 & 27 & 17 \\
$70-74$ & 289 & 390 & 8 & 12 \\
$75-79$ & 380 & 520 & 0 & 16 \\
$80+$ & 1,249 & 1,170 & 116 & 50 \\
\hline
\end{tabular}

TABLE V

Fracture Rates in Dundee, in Malmö and in Johannesburg Bantu Applied to a Standard Population (THe Standard United States Population for 1950) to Show the Comparative Rates PER 100,000 per AnNum

\begin{tabular}{|c|c|c|c|c|c|}
\hline \multirow{2}{*}{$\underset{\text { (years) }}{\text { Age }}$} & \multirow{2}{*}{$\begin{array}{c}\text { Standard } \\
\text { population } \\
\text { (U.S.A.) }\end{array}$} & \multicolumn{4}{|c|}{ Standardised fracture rates per annum } \\
\hline & & $\begin{array}{c}\text { Dundee } \\
\text { (females) }\end{array}$ & $\begin{array}{c}\text { Malmö } \\
\text { (females) }\end{array}$ & $\begin{array}{l}\text { Bantu } \\
\text { males }\end{array}$ & $\begin{array}{l}\text { Bantu } \\
\text { females }\end{array}$ \\
\hline Under 30 & 496,512 & & & & \\
\hline $30-34$ & 76,425 & & & $2 \cdot 5$ & 0 \\
\hline $35-39$ & 74,629 & & & $1 \cdot 7$ & 1.0 \\
\hline $40-44$ & 67,712 & & & $2 \cdot 1$ & $2 \cdot 3$ \\
\hline $45-49$ & 60,190 & & & $2 \cdot 0$ & 0.5 \\
\hline $50-54$ & 54,893 & $3 \cdot 3$ & $21 \cdot 9$ & $3 \cdot 1$ & $2 \cdot 0$ \\
\hline $55-59$ & 48,011 & $15 \cdot 8$ & $33 \cdot 6$ & $4 \cdot 7$ & $5 \cdot 8$ \\
\hline $60-64$ & 40,210 & $14 \cdot 9$ & $48 \cdot 3$ & $5 \cdot 5$ & $6 \cdot 8$ \\
\hline $65-69$ & 33,199 & $45 \cdot 8$ & $73 \cdot 0$ & $8 \cdot 8$ & $4 \cdot 1$ \\
\hline $70-74$ & 22,641 & $65 \cdot 4$ & $88 \cdot 3$ & $1 \cdot 8$ & $3 \cdot 7$ \\
\hline $75-79$ & 14,725 & $56 \cdot 0$ & $76 \cdot 6$ & 0 & $7 \cdot 4$ \\
\hline $80+$ & 10,853 & $135 \cdot 6$ & $127 \cdot 0$ & $12 \cdot 6$ & $8 \cdot 7$ \\
\hline Total & $1,000,000$ & $336 \cdot 8$ & $468 \cdot 7$ & $44 \cdot 8$ & $42 \cdot 3$ \\
\hline Rate per 100,000 & & $33 \cdot 7$ & 46.9 & $4 \cdot 5$ & $4 \cdot 2$ \\
\hline
\end{tabular}


In both Stewart's and Bauer's series the fracture rates in females were almost doubled in each successive five-year period over the age of sixty, whereas males were affected much less frequently. A survey among hospital patients in Johannesburg indicates that a similar fracture pattern occurs in the white South Africans of European descent (Solomon 1965). In the Bantu, however, there was no significant difference between the male and female fracture rates.

\section{DISCUSSION}

Seftel et al. (1963) and Seftel, Malkin, Schmaman, Abrahams, Lynch, Charlton and Bothwell (1966) described a peculiar type of osteoporosis of the spine in the Bantu of Johannesburg. Although its exact prevalence has not been ascertained, it is relatively uncommon in comparison with senile osteoporosis in European communities. It occurs predominantly in males and has its greatest incidence in the fifth decade. It is associated with haemosiderosis and scurvy and may be related to the high iron content of the local Bantu beer. It should be stressed that this condition is quite distinct from " senile " or " post-menopausal " osteoporosis and that none of these patients has presented with fracture of the femoral neck.

The cause of " senile" osteoporosis is still unknown, though not for the lack of plausible theories. Albright and his co-workers (Albright, Bloomberg and Smith 1940; Albright 1947) first postulated that the decline of gonadal activity in old age led to defective osteoblastic activity and caused osteoporosis by a diminution of bone formation. To this Reifenstein (1957) added the concept of a relatively lesser decline in adrenal activity leading to an excess of anti-anabolic steroids and a further retardation of bone formation. The earlier and more pronounced occurrence of these changes in women explained the difference in sex incidence which has given rise to the term " post-menopausal" osteoporosis.

This general hypothesis was not seriously questioned until tracer studies of bone " accretion rates" with radioactive calcium and strontium indicated that osteoporosis was probably not associated with decreased bone formation (Heaney and Whedon 1958; Nordin 1959; Nordin, Dallas, MacGregor and Smith 1964). From this it has been adduced that the immediate cause of osteoporosis is increased bone resorption and this concept has been strongly supported by microradiographic studies of normal and osteoporotic human bone (Jowsey 1960; Sissons, Jowsey and Stewart 1960; Jowsey, Kelly, Riggs, Bianco, Scholz and Gershon-Cohen 1965).

The cause of this increase in bone resorption is still a matter of controversy, though following the work of Heaney and Whedon $(1958)$, Nordin $(1959,1961)$ and Harrison, Fraser and Mullan (1961), there has been a tendency to attribute it to a chronic low grade calcium deficiency, possibly associated with an inability to conserve calcium by reducing calcium excretion. The fact that osteoporosis can be produced in the experimental animal by keeping it on a diet deficient in calcium but with adequate vitamin D (Bauer, Aub and Albright 1929; Bell, Cuthbertson and Orr 1941; Harrison and Fraser 1960; Jowsey and Gershon-Cohen 1964) has further strengthened this argument.

These theories have been examined more closely in the light of the findings presented here. Endocrine factors-There is good evidence of a rise in the incidence of fractures which may reasonably be attributed to osteoporosis over the age of sixty years. It is less certain, however, that the endocrine changes postulated by Albright and Reifenstein are the sole cause, or even a major contributory cause, of this trend. The fracture rate in Bantu women is much lower than in white women, yet the age of the menopause is identical in these two groups. Moreover, there is no significant difference in the incidence of fractures in Bantu men and women. These findings are supported by the results of a radiographic survey of vertebral osteoporosis in a rural Bantu community which will be reported in detail at a later date.

Calcium deficiency-Theoretically there are three ways of producing a chronic negative calcium balance: by a diminished intake of calcium; by deficient absorption of calcium; and by increased excretion of calcium.

VOL. 50 B, NO. 1, FEBRUARY 1968 
Nordin (1961), Dallas and Nordin (1962) and Lutwak (1963) reported that calcium intake was significantly reduced in osteoporotic patients. This contention has been difficult to support, partly because up to the present time there has been no satisfactory estimate of the minimum calcium requirements for humans. Certainly the Recommended Dietary Allowances of the National Research Council in the United States ( 800 milligrams per day for adults) are now considered to be too high, and the World Health Organisation's Expert Group on Calcium Requirements, which was unable to establish an exact minimum requirement, suggested a "practical allowance" of 400-500 milligrams per day for adults (Food and Agriculture Organisation of the United Nations Report on Calcium Requirements 1962). Furthermore, it has been shown that most, though not all, people are capable of " adapting " to marked reductions in calcium intake and maintaining a positive calcium balance by reducing the faecal calcium excretion (Hegsted, Moscoso and Collazos 1952; Malm 1958; Nicolaysen 1960; Harrison 1963). However, this work was carried out under experimental conditions and the contention that osteoporosis is a "calcium deficiency disease " has not previously been tested by any formal epidemiological study of its incidence in poor population groups receiving a "low calcium diet."

The Bantu population studied in the present investigation is poor by present-day Western standards. Socio-economic surveys of the Johannesburg townships during the last twelve years showed that about half of the families received an income below the poverty level (South African Institute of Race Relations 1957, Higginson and Oettle 1960). The calcium intake of this population has been assessed at 200-450 milligrams per day (Walker, Arvidsson and Politzer 1954). In the case of the women the calcium reserves are further strained by frequent pregnancies and the custom of prolonged breast feeding. Yet the present study has shown that advanced osteoporosis, as indicated by femoral neck fractures, is far less prevalent in the urban Bantu than in white people. It is difficult to escape the conclusion that senile osteoporosis is not due to a simple " calcium deficiency."

There remain the possibilities that a chronic negative calcium balance may be induced by deficient intestinal absorption or hypercalciuria. Nordin and his associates (1964) could not find any absolute difference in urinary calcium excretion between normal and osteoporotic subjects but suggested that the latter were less able to adapt their urinary calcium excretion to a low calcium diet. However, although there are wide variations in the normal urinary calcium levels of different people, calcium excretion is remarkably constant for any one individual, and there is little evidence that it is greatly influenced by changes in calcium intake. In subjects habituated to a low calcium diet the urinary calcium excretion is slightly lower than in those accustomed to a high calcium diet. Even so, it is most unlikely that this small difference could account for the vastly different distribution of osteoporosis in Bantu and white communities (Jackson 1961). If the concept of "calcium deficiency" as a cause of osteoporosis is to retain any validity, therefore, it should be reformulated as a failure in the complex balance between calcium intake, calcium excretion and total calcium absorptionor else as a deficiency of some, as yet unknown, endogenous factor which normally controls this balance. There is evidence that intestinal calcium absorption is closely related to the normal level of urinary calcium excretion for each individual (Knapp 1947; Nicolaysen, Eeg-Larsen and Malm 1953; Nicolaysen 1960), and Malm (1958) has shown that healthy men are capable of considerable adaptation to a reduction in calcium intake, without as great a reduction in urinary calcium, by increased intestinal absorption. Moreover, Kinney, Tauxe and Dearing (1963), in a study of normal and osteoporotic subjects, found that half of those with osteoporosis showed deficient absorption of calcium.

Racial factors-Whatever the immediate cause of osteoporosis in the aged, there can be little doubt, on the basis of this study, that race plays an important if not a dominant part in its manifestation. This conclusion is supported by studies on the relationship of bone density changes to age, sex and race. Broman, Trotter and Peterson (1958) and Trotter, Broman and 
Peterson (1960) determined bone densities in the skeletons of American negroes and whites. They found that within each sex and race group bone density decreased progressively with age, but throughout the age range studied the bones of the negro skeleton are denser than those of the white skeleton. Similar differences have been found in the vertebrae of white and Bantu subjects (Walker, Strydom Reynolds and Grobbelaar 1955).

Further epidemiological studies now in progress suggest that, while " senile " osteoporosis does occur in all race groups in South Africa, it appears at a later age and is much less severe and less widespread in the Bantu than in white subjects. The factors determining the racial difference are still obscure. Their elucidation may contribute significantly to our understanding of this condition.

\section{SUMMARY}

1. Senile osteoporosis is one of the common causes of morbidity in old people. Its distribution in European and American populations has been deduced from epidemiological studies of its major complications, such as fractures of the vertebrae and the femoral neck. Although there has been some evidence that different population groups differ in their susceptibility to this condition, no demographic study of its prevalence in the white and Bantu races has previously been made.

2. The present paper describes an epidemiological study of femoral neck fractures in the Bantu population of Johannesburg, covering the years 1957-63. The cases were analysed by age and sex, the type of trauma and the level of the fracture. The number of fractures was related to the population at risk; the fracture incidence was expressed both as an age-specific rate and as a standardised rate and compared with fracture rates in European populations. It was found that the fracture rate in the elderly Bantu is less than one-tenth of that in Western European populations, and that males and females are affected equally. It was concluded that senile or post-menopausal osteoporosis is much less pronounced in the Bantu than in white populations.

3. The relationship of these findings to endocrine changes, calcium balance and racial factors is discussed. It is suggested that senile osteoporosis is not caused by a simple calcium deficiency but may be related to an imbalance between calcium intake, absorption and excretion, or a failure of the complex mechanism which normally controls this balance. Whatever the immediate cause, however, race plays an important part in determining the onset and distribution of the condition.

I am deeply indebted to Dr W. G. Hearn for his assistance in organising the survey of Bantu invalids. I also wish to thank the Superintendents of the Johannesburg General Hospital, Coronation Hospital and Baragwanath Hospital for allowing me to have access to patients and records and for permission to publish these findings. I am most grateful, too, to Dr G. Oettle for his expert advice on the presentation of the demographic facts.

\section{REFERENCES}

Albright, F. (1947): Osteoporosis. Annals of Internal Medicine, 27, 861.

Albright, F., Bloomberg, E., and Smith, P. H. (1940): Post-menopausal Osteoporosis. Transactions of the Association of American Physicians, 55, 298.

Batson, E., and Feldman, G. R. (1951): Report on a Sample Survey of the Native Population Residing in the Western Areas of Johannesburg. City of Johannesburg Non-European Affairs Department.

Bauer, G. C. H. (1960): Epidemiology of Fracture in Aged Persons. Clinical Orthopaedics, 17, 219.

Bauer, W., Aub, J. C., and Albright, F. (1929): Studies of Calcium and Phosphorus Metabolism. V. A Study of the Bone Trabeculae as a Readily Available Reserve Supply of Calcium. Journal of Experimental Medicine, 49, 145.

Bell, G. H., Cuthbertson, D. P., and OrR, J. (1941): Strength and Size of Bone in Relation to Calcium Intake. Journal of Physiology, 100, 299.

Bollet, A. J., Engh, G., and Parson, W. (1965): Epidemiology of Osteoporosis. Archives of Internal Medicine, 116, 191.

VOL. $50 \mathrm{~B}$, NO. 1, FEBRUARY 1968 
Broman, G. E., Trotter, M., and Peterson, R. R. (1958): The Density of Selected Bones of the Human Skeleton. American Journal of Physical Anthropology, N.S. 16, 197.

BuHr, A. J., and CoOKe, A. M. (1959): Fracture Patterns. Lancet, i, 531.

COOPER, A. (1824): A Treatise on Dislocations, and on Fractures of the Joints. Fourth edition. London: Longmans.

Dallas, I., and Nordin, B. E. C. (1962): The Relation Between Calcium Intake and Roentgenologic Osteoporosis. American Journal of Clinical Nutrition, 11, 263.

FoOd ANd Agriculture Organisation of the United Nations (1962): Calcium Requirements. World Health Organisation Technical Report Series, No. 230.

Gershon-Cohen, J., Rechtman, A. M., Schraer, H., and Blumberg, N. (1953): Asymptomatic Fractures in Osteoporotic Spines of the Aged. Journal of the American Medical Association, 153, 625.

GyePeS, M., Mellins, H. Z., and KatZ, I. (1962): The Low Incidence of Fracture of the Hip in the Negro. Journal of the American Medical Association, 181, 1073.

Harrison, H. E. (1963): Symposium on Human Calcium Requirements. Journal of the American Medical Association, 185, 589.

Harrison, M., and Fraser, R. (1960): Bone Structure and Metabolism in Calcium-deficient Rats. Journal of Endocrinology, 21, 197.

Harrison, M., Fraser, R., and Mullan, B. (1961): Calcium Metabolism in Osteoporosis. Lancet, i, 1015.

Heaney, R. P., and Whedon, G. D. (1958): Radiocalcium Studies of Bone Formation Rate in Human Metabolic Bone Disease. Journal of Clinical Endocrinology, 18, 1246.

Hearn, W. G. (1964): Invalidism in an Urban Bantu Community. South African Medical Journal, 38, 958.

Hegsted, D. M., Moscoso, I., and Collazos, C. (1952): A Study of the Minimum Calcium Requirements of Adult Men. Journal of Nutrition, 46, 181.

Higginson, J., and Oetrté, A. G. (1960): Cancer Incidence in the Bantu and " Cape Colored " Races of South Africa: Report of a Cancer Survey in the Transvaal (1953-55). Journal of the National Cancer Institute, $24,589$.

JACKson, W. P. U. (1961): Some Aspects of Calcium Metabolism in Human Adults. What is Normal? Calcium Metabolism in Man. N.V. Nutritia Symposium (Zoetermeer) (Also Voeding, 22, 617).

Jowsey, J. ( 1960): Age Changes in Human Bone. Clinical Orthopaedics, 17, 210.

Jowsey, J., and Gershon-CoHEN, J. (1964): Effect of Dietary Calcium Levels on Production and Reversal of Experimental Osteoporosis in Cats. Proceedings of the Society for Experimental Biology and Medicine, 116, 437.

Jowsey, J., Kelly, P. J., Riggs, B. L., Bianco, A. J., Jun., Scholz, D. A., and Gershon-Cohen, J. (1965): Quantitative Microradiographic Studies of Normal and Osteoporotic Bone. Journal of Bone and Joint Surgery, 47-A, 785.

KINNeY, V. R., TAUXe, W. N., and Dearing, W. H. (1963): Absorption of Radiocalcium and its Relation to Dietary Calcium. (Abstract.) Proceedings of the Central Society for Clinical Research, thirty-sixth annual meeting. Journal of Laboratory and Clinical Medicine, 62, 989.

KNAPP, E. L. (1947): Factors Influencing the Urinary Excretion of Calcium. Journal of Clinical Investigation, 26, 182.

LuTwaK, L. (1963): Osteoporosis: A Disorder of Nutrition. New York State Journal of Medicine, 63, 590.

MaLm, O. J. (1958): Calcium Requirement and Adaptation in Adult Men. Scandinavian Journal of Clinical and Laboratory Investigation, 10, Supplement 36.

Nicolaysen, R. (1960): The Calcium Requirement of Man As Related to Diseases of the Skeleton. Clinical Orthopaedics, 17, 226.

Nicolaysen, R., Eeg-Larsen, N., and Malm, O. J. (1953): Physiology of Calcium Metabolism. Physiological Reviews, 33, 424.

Nordin, B. E. C. (1959): Investigation of Bone Metabolism with ${ }^{47} \mathrm{Ca}$. Proceedings of the Royal Society of Medicine, 52, 351.

Nordin, B. E. C. (1961): The Pathogenesis of Osteoporosis. Lancet, i, 1011.

Nordin, B. E. C. (1963): Osteoporosis. In Bone Metabolism in Relation to Clinical Medicine, p. 113. Ed. H. A. Sissons. London: Pitman Medical Publishing Co. Ltd.

Nordin, B. E. C., Dallas, I., MacGregor, J., and Smith, D. A. (1964): The Pathogenesis of Osteoporosis. In L'Osteoporose. Symposium Organisé Par Le Centre Due Métabolisme Phospho-Calcique, p. 216. Publié par D. J. Hioco. Paris: Masson \& Cie.

Oetrle, A. G. (1955): Problems of Research into Diseases of the Bantu. South African Journal of Laboratory and Clinical Medicine, 1, 57.

OetTLE, A. G. (1958): Statistical Techniques for Examining Racial Differences in Tumour Incidence. Leech, $28,40$.

Reifenstein, E. C., Jun. (1957): The Relationships of Steroid Hormones to the Development and the Management of Osteoporosis in Aging People. Clinical Orthopaedics, 10, 206.

Reifenstein, E. C., Jun. (1960): Discussion: Osteoporosis. In Bone as a Tissue, p. 83. Ed. K. Rodahl, J. T. Nicholson and E. M. Brown, Jun. New York, Toronto, London: McGraw Hill Book Co. Inc. 
Seftel, H. C., Abrams, G. J., Charlton, R. W., Abrahams, C., Rubenstein, A., Jacobs, P., and Bothwell, T. H. (1963): Osteoporosis and Siderosis in Africans. South African Journal of Medical Science, 28, 115.

Seftel, H. C., Malkin, C., Schmaman, A., Abrahams, C., Lynch, S. R., Charlton, R. W., and Bothwell, T. H. (1966): Osteoporosis, Scurvy, and Siderosis in Johannesburg Bantu. British Medical Journal, i, 642.

Sissons, H. A., Jowsey, J., and StewART, L. (1960): The Microradiographic Appearance of Normal Bone Tissue at Various Ages. X-ray Microscopy and X-ray Microanalysis. Proceedings of the Second International Symposium, p. 206. Ed. A. Angström, V. Cosslett, and H. Pattee. Amsterdam: Elsevier Publishing Company.

Smith, R. W., Eyler, W. R., and Mellinger, R. C. (1960): On the Incidence of Senile Osteoporosis. Annals of Internal Medicine, 52, 773.

SOLOMON, L. (1965): Unpublished data.

South African Institute of Race Relations (1957): African Poverty. Johannesburg: Published by South African Institute of Race Relations.

Stevens, J., Freeman, P. A., Nordin, B. E. C., and Barnetr, E. (1962): The Incidence of Osteoporosis in Patients with Femoral Neck Fracture. Journal of Bone and Joint Surgery, 44-B, 520.

STEWART, I. M. (1955): Fractures of Neck of Femur. Incidence and Implications. British Medical Journal, i, 698.

StewART, I. M. (1958): Fracture of Neck of Femur. The Rate Risk and Casualty Planning. Medical Officer, $100,100$.

Trotter, M., Broman, G. E., and Peterson, R. R. (1960): Densities of Bones of White and Negro Skeletons. Journal of Bone and Joint Surgery, 42-A, 50.

Urist, M. R. (1960): Observations Bearing on the Problem of Osteoporosis. In Bone as a Tissue, p. 18. Ed. K. Rodahl, J. T. Nicholson and E. M. Brown. New York: McGraw Hill Book Co. Inc.

VINCENT, P. J., and URIST, M. R. (1961): The Appearance of Osteoporosis In Ambulatory Institutionalized Males. Clinical Orthopaedics, 19, 245.

Vose, G. P., Stover, B. J., and Mack, P. B. (1961): Quantitative Bone Strength Measurements in Senile Osteoporosis. Journal of Gerontology, 16, 120.

Walker, A. R. P. (1965): Osteoporosis and Calcium Deficiency. American Journal of Clinical Nutrition, 16, 327.

Walker, A. R. P., Arvidsson, U. B., and Politzer, W. M. (1954): Significance of Low Serum Calcium Values in South African Bantu. South African Medical Journal, 28, 48.

Walker, A. R. P., Strydom, E. S. P., Reynolds, P. A., and GrobbelaAr, B. G. (1955): The Composition and Density of Thoracic Vertebral Bodies from South African Bantu Adults Habituated to a Very High Iron Intake. South African Journal of Laboratory and Clinical Medicine, 1, 254.

VOL. $50 \mathrm{~B}$, NO. 1, FEBRUARY 1968 